\title{
Policy options for increasing the supply of transplantable kidneys in Singapore
}

Jia Loon Chong, BEng

\begin{abstract}
Kidney transplantation is the preferred treatment for eligible end-stage renal disease patients. However, the supply of donated kidneys has been consistently insufficient to meet the transplantation requirements of the population. In this paper, I discuss the feasibility of several policy options that engage potential donors or key individuals in a Singapore context, including financial and non-financial incentives for deceased/living organ donors and their families, improving actualisation rates of both donation after brain death, donation after cardiac death through quality improvement programmes and remuneration schemes, and a media platform for directed organ donation. I conclude by highlighting the most feasible policies to be considered.
\end{abstract}

Keywords: end-stage renal disease, kidney donation, Singapore, transplantation

\section{INTRODUCTION}

Chronic kidney disease (CKD) is a worldwide public health problem that is increasing in incidence, prevalence, morbidity and cost. ${ }^{(1)}$ In Singapore, CKD is the ninth leading cause of death, ${ }^{(2)}$ while the incidence of end-stage renal disease (ESRD) increased from 680 cases in 1999 to 1,405 cases in $2010 .^{(3)}$ Due to Singapore's ageing population, this number is projected to increase sharply. ${ }^{(4)}$ Among the treatment options for ESRD patients, kidney transplantation is the treatment of choice for medically eligible patients, as it is more cost-effective than dialysis. ${ }^{(2,5)}$ However, there are insufficient available, transplantable kidneys to meet demand and the median waiting time for a kidney transplant can be as long as nine years in Singapore, compared to 3-5 years in the United States, Australia or the United Kingdom. ${ }^{(6)}$ Fig. 1 provides an overview of the dynamics behind Singapore's supply and demand of transplantable kidneys and suggests reasons for the lack of transplantable kidneys. ${ }^{(7)}$ Detailed explanations are available in the online supplementary document (http://www.smj.org.sg/ sites/default/files/CO-policy-Supplementary.pdf). In this article, I explored policies that could engage potential donors and key individuals through incentives or their sense of altruism in the Singapore context.

\section{Financial incentives for deceased donors and their families}

Proponents of market-like schemes often assert that altruism is fixed in supply or that the cost of appealing to altruistic motivations is prohibitively high. ${ }^{(8,9)}$ However, introducing posthumous financial incentives may paradoxically lead to relatives imputing a weaker preference for organ donation on the part of the deceased, hence increasing the likelihood that relatives refuse to consent to organ harvesting. ${ }^{(10)}$ Furthermore, such legislation is unlikely to be feasible in Singapore due to societal repugnance toward 'organ-selling'.(11)

\section{Non-financial incentives for deceased donors and their families}

Non-financial incentives may still be feasible to potential donors and their relatives. Israel, for example, has achieved measurable success (e.g. increasing from 7.8 to 11.4 donors per million population in 2010 and 2011, respectively) through its policy of encouraging deceased donation by giving priority on the organ transplant list to registered/actualised donors and close relatives who consent to successful posthumous donation, should they themselves ever require donated organs. ${ }^{(12)}$ In Singapore, such measures could apply to the relatives of terminally ill patients (with no hope for survival) who agree to donation through controlled terminal extubation.

\section{Regulated financial incentives for living donors}

Proponents of self-interest-based incentives argue that waiting lists for kidney transplantation could disappear with the formation of a government-controlled market similar to the Iranian model. ${ }^{(13)}$ In this model, there would be no middleman or exploitation of low-income countries and their populations, as only health-screened citizens are allowed to donate, and organs are allocated based on compatibility and need. However, there are concerns that kidney sales may lead to coercion of socioeconomically disadvantaged populations. Sellers may also suffer significant shame, as observed in Iran. ${ }^{(14)}$ Additionally, 'crowding out' may lead to a reduction in altruistic donations; this was observed in Hong Kong after its reunification with China made it easier to purchase kidneys from China. ${ }^{(15)}$ In light of this, outlawing kidney sales under the Human Organ Transplant Act (HOTA), ${ }^{(16)}$ as well as punitive measures against medical and allied health personnel facilitating such transplants, helps Singapore to avoid many of the negative repercussions of an organ market.

Nonetheless, HOTA does allow financial reimbursements for living donors (LDs) in cases of transplantation-related 


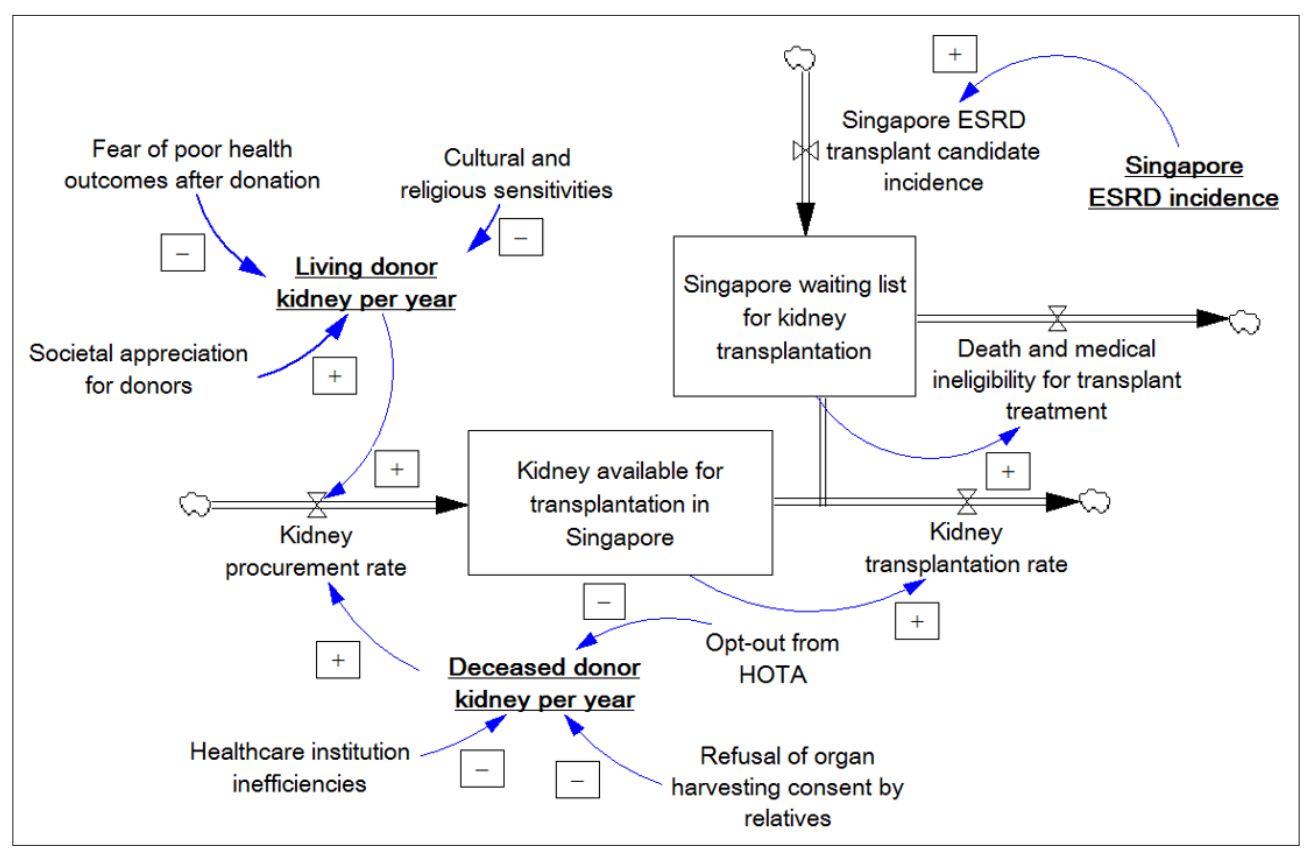

Fig. 1 Stock and flow diagram ${ }^{(7)}$ shows an overview of the dynamics behind the supply and demand of transplantable kidneys in Singapore. ESRD: endstage renal disease; HOTA: Human Organ Transplant Act

loss-of-income, medical fees and insurance premiums. ${ }^{(16,17)}$ This does not equate to the commercialisation of transplantation, as donors do not receive net financial profit from their donation. Such reimbursements help provide peace of mind to potential donors by protecting them from untoward medical complications as a result of their donation.

\section{Non-financial incentives for living donors}

Another way to overcome social repugnance is to structure incentives that are likely to be widely accepted, such as nonfinancial incentives. For example, LDs in Saudi Arabia receive permanent discounts if they travel via Saudi Arabian Airlines and may even be awarded the King Abdul Aziz Medal of the third degree; ${ }^{(18)}$ in Israel, LDs are known to be compensated with free admission to the country's national parks, ${ }^{(18)}$ as well as preferential status as an organ recipient should they ever require a transplant. ${ }^{(19)}$ Given the need to avoid social repugnance in Singapore, this may be a more viable option for expressing appreciation to LDs. Increased societal respect for LDs may encourage more individuals to volunteer to be LDs.

\section{Improving donation after cardiac death and donor actualisation rates through quality improvement programmes and remuneration schemes}

Physicians and hospital staff may view involvement with donations as a bothersome task that puts them at risk of malpractice litigation and distracts them from attending to their living patients. ${ }^{(8)}$ Of note, steps such as donor identification and informing distraught relatives of organ donation are examples of critically important, yet difficult, ${ }^{(20)}$ steps in the actualisation process of a potential donor. In this regard, Singapore has room for improvement given the large inter-hospital variance ${ }^{(20)}$ in donor actualisation rates and very low rates of donation after cardiac death $(\mathrm{DCD})^{(21)}$ despite permissive legislation under HOTA. ${ }^{(22)}$

Spain, which doubled organ donation rates in ten years, optimises actualisation rates by holding transplant coordinators and healthcare authorities accountable through staff training, ${ }^{(23)}$ indirect financial incentives and full disclosure of healthcare institutions' organ donation results. ${ }^{(24)}$ Meanwhile, several European countries including Spain, Belgium, the Netherlands and Britain are noted to have some of the highest kidney DCD rates worldwide. ${ }^{(25)}$ Thus, it is worthwhile to study the characteristics of the DCD programmes in these countries. ${ }^{(26)}$ Replicating their success in Singapore is technically feasible, but would require significant public education efforts and increased coordination between medical and allied health personnel.

A multipronged approach can be considered, namely through organising quality improvement (QI) programmes in which transplant teams take responsibility for improving the organ transplantation process (e.g. identification of potential DCD donors, educating families about donation, post-controlled terminal extubation, etc) in their respective institutions, as well as increased personnel incentive schemes. Increased remuneration to personnel for their time and an effort to identify and actualise potential deceased donors (DDs) is a fair measure that does not equate to the commercialisation of transplantation.

\section{Media platform for directed organ donation}

Proponents of altruism often stress the importance of donations based on solidarity, and that the donor's sole motivation should be to save a life and thereby feel proud of their deed. ${ }^{(27)}$ Directed organ donation by a stranger through public advertisement platforms (e.g. matchingdonors.com) is technically legal in countries that have legalised unrelated donation, such as the 
United States ${ }^{(28)}$ and Singapore. ${ }^{(29)}$ Such platforms increase the marginal propensity of the public to donate, possibly through the identifiable victim effect. ${ }^{(30)}$

Unrelated donations are illegal in a number of countries due to some concerns, including suspicions of ulterior, undeclared financial motives. ${ }^{(31)}$ At the same time, directed unrelated donations may also be viewed as inequitable, as the donated organ may not be allocated based on need. ${ }^{(28)}$ Nonetheless, with directed unrelated donations, we are able to ensure that at least some patients benefit; hence, platforms that encourage such interactions may potentially still be viable in Singapore.

\section{Recommendations}

In order to increase the number of LDs within the existing regulatory framework, non-repugnant incentives can be considered, such as an organ donation award that not only recognises the significance of the donor's act but also creates meaningful conversation on the importance of organ donation in saving lives. In addition, local online platforms can be created to help ESRD patients appeal to the public for directed kidney donations.

Meanwhile, in order to increase the number of DDs, it is critically important to establish administrative incentives for healthcare professionals to take responsibility for improving the organ transplantation process through QI programmes. Therefore, measures that can be considered include stronger incentives and training for personnel involved in donor-identification, coupled with greater transparency for both individual hospital DD actualisation rates and DCD statistics. Finally, potential donors and their immediate families can be further incentivised through a transplant priority system which favours donors' families.

In conclusion, greater measures to encourage and facilitate donation can be implemented at all levels to meet society's transplantation needs. Moving forward, all relevant institutions in Singapore are encouraged to contribute their insights and experience in increasing the supply of kidneys for transplantation so that a meaningful national conversation can commence and best practices adopted to address this urgent shortage.

\section{ACKNOWLEDGEMENTS}

I would like to thank Professor David Bruce Matchar, Mr Choong Zichao and Ms Crystal Lim for their input, which helped improve the content of this article.

\section{REFERENCES}

1. Levey AS, Coresh J, Balk E, et al; National Kidney Foundation. National Kidney Foundation practice guidelines for chronic kidney disease: evaluation, classification, and stratification. Ann Intern Med 2003; 139:137-47.

2. Meng OY, Lim C, Leng CW, et al. Factors influencing living kidney donation in Singapore. Prog Transplant 2012; 22:95-101.

3. National Registry of Diseases Office, Singapore. Health Factsheet. Trends of End Stage Renal Disease in Singapore. 2013 Feb 27. Available at: https:/ www.nrdo.gov.sg/docs/librariesprovider3/Publications---Kidney-Failure/ health_factsheet_esrd_2013feb.pdf?sfvrsn=0. Accessed February 21, 2016.

4. Department of Statistics Singapore. Population Trends 2015. Available at: http://www.singstat.gov.sg/publications/publications-and-papers/ population-and-population-structure/population-trends. Accessed February 21, 2016.

5. Abecassis M, Bartlett ST, Collins AJ, et al. Kidney transplantation as primary therapy for end-stage renal disease: a National Kidney Foundation/Kidney Disease Outcomes Quality Initiative (NKF/KDOQITM) conference. Clin J Am Soc Nephrol 2008; 3:471-80.

6. Teo BW, Demirjian S. World kidney day 2012: renal transplantation. Ann Acad Med Singapore 2012; 41:96-7.

7. Brailsford SC. System dynamics: what's in it for healthcare simulation modelers. In: Mason SJ, Hill RR, Monch L, et al, eds. Proceedings of the 2008 Winter Simulation Conference. Winter Simulation Conference. New York: Institute of Electrical and Electronics Engineering, 1478-83.

8. Thorne ED. The economics of organ transplantation. In: Kolm SC, Ythier JM, eds. Handbook of the Economics of Giving, Altruism and Reciprocity Vol 2. Elsevier, 2006: 1335-70.

9. Becker GS, Elias JJ. Introducing incentives in the market for live and cadaveric organ donations. J Econ Perspect 2007; 21:3-24.

10. Byrne MM, Thompson P. A positive analysis of financial incentives for cadaveric organ donation. J Health Econ 2001; 20:69-83.

11. Roth AE. Repugnance as a constraint on markets. J Econ Perspect 2007; 21:37-58.

12. Roth AE. Transplantation: one economist's perspectives. Transplantation 2015; 99:261-4.

13. Ghods AJ, Savaj S. Iranian model of paid and regulated living-unrelated kidney donation. Clin J Am Soc Nephrol 2006; 1:1136-45.

14. Rothman SM, Rothman DJ. The hidden cost of organ sale. Am J Transplant 2006; 6:1524-8.

15. Danovitch GM, Leichtman AB. Kidney vending: the "Trojan horse" of organ transplantation. Clin J Am Soc Nephrol 2006; 1:1133-5.

16. Chin JJ, Kwok TH. After presumed consent: a review of organ donation in Singapore. Indian J Med Ethics 2014; 11:139-43.

17. National Kidney Foundation, Singapore. Kidney Live Donor Support Fund. Available at: http://www.nkfs.org/treatment/kidney-transplant/kidney-livedonor-support-fund/. Accessed April 9, 2016.

18. Sickand M, Cuerden MS, Klarenbach SW, et al; Donor Nephrectomy Outcomes Research Network. Reimbursing live organ donors for incurred non-medical expenses: a global perspective on policies and programs. Am J Transplant 2009; 9:2825-36.

19. Zúñiga-Fajuri A. Increasing organ donation by presumed consent and allocation priority: Chile. Bull World Health Organ 2015; 93:199-202.

20. Kwek TK, Lew TW, Tan HL, Kong S. The transplantable organ shortage in Singapore: has implementation of presumed consent in organ donation made a difference? Ann Acad Med Singapore 2009; 38:346-8.

21. Bendorf A, Kelly PJ, Kerridge IH, et al. An international comparison of the effect of policy shifts to organ donation following cardiocirculatory death (DCD) on donation rates after brain death (DBD) and transplantation rates. PLoS One 2013; 8:e62010.

22. Shum E, Chern A. Amendment of the Human Organ Transplant Act. Ann Acad Med Singapore 2006; 35:428-32.

23. Mirandaa B, Vilardell J, Grinyó JM. Optimizing cadaveric organ procurement: the catalan and Spanish experience. Am J Transplant 2003; 3:1189-96.

24. McMaster $\mathrm{P}$, Vadeyar $\mathrm{H}$. Spain model: world leaders in organ donation. Liver Transpl 2000; 6:501-3.

25. Summers DM, Watson CJ, Pettigrew GJ, et al. Kidney donation after circulatory death (DCD): state of the art. Kidney Int 2015; 88:241-9.

26. Domínguez-Gil B, Haase-Kromwijk B, Van Leiden $\mathrm{H}$, et al; European Committee (Partial Agreement) on Organ Transplantation, Council of Europe (CD-P-TO). Current situation of donation after circulatory death in European countries. Transpl Int 2011; 24:676-86.

27. Garwood P. Dilemma over live-donor transplantation. Bull World Health Organ 2007; 85:5-6.

28. Truog RD. The ethics of organ donation by living donors. New Engl J Med 2005; 353:444-6.

29. Organ Donation - Facts. In: Live On - Support Organ Donation [online]. Available at: https://www.liveon.sg/content/moh_liveon/en/organdonation/ facts.html. Accessed February 21, 2016.

30. Jenni KE, Loewenstein G. Explaining the "identifiable victim effect". J Risk Uncertainty 1997; 14:235-57.

31. Jingwei $A H$, $\mathrm{Yu}-\mathrm{Hung} \mathrm{AL}$, Ching L. Living organ transplantation policy transition in Asia: towards adaptive policy changes. Global Health Governance 2010; 3. 